\title{
RELATIONSHIPS BETWEEN PARENTING STYLES AND RISK BEHAVIORS IN ADOLESCENT HEALTH: AN INTEGRATIVE LITERATURE REVIEW
}

\author{
Kathy Newman ${ }^{1}$ \\ Lynda Harrison ${ }^{2}$ \\ Carol Dashiff ${ }^{2}$ \\ Susan Davies ${ }^{3}$
}

Newman K, Harrison L, Dashiff C, Davies S. Relationships between parenting styles and risk behaviors in adolescent health: an integrative literature review. Rev Latino-am Enfermagem 2008 janeiro-fevereiro; 16(1):142-50.

Research over the past 20 years suggests that the quality of the parent-adolescent relationship significantly affects the development of risk behaviors in adolescent health. The purpose of this paper is to present a review of studies published between 1996-2007 that address specific relationships between parenting styles and six priority adolescent risk behaviors. The review supports the substantial influence of parenting style on adolescent development. Adolescents raised in authoritative households consistently demonstrate higher protective and fewer risk behaviors than adolescents from non-authoritative families. There is also considerable evidence to show that parenting styles and behaviors related to warmth, communication and disciplinary practices predict important mediators, including academic achievement and psychosocial adjustment. Careful examination of parenting style patterns in diverse populations, particularly with respect to physical activity and unintentional injury, will be a critical next step in the development of efficacious, culturally tailored adolescent health promotion interventions.

DESCRIPTORS: adolescent behavior; risk-taking; adolescent health; parent-child relations

\section{RELACIONES ENTRE LOS TIPOS DE PADRES Y COMPORTAMIENTOS DE RIESGO EN LA SALUD DEL ADOLESCENTES: UNA REVISIÓN BIBLIOGRÁFICA INTEGRADA}

Resultados de investigaciones realizadas durante los últimos 20 años muestran que la calidad en las relaciones entre padres e hijos ha provocado un impacto significativo en el desarrollo de comportamientos de riesgo para la salud del adolescente. El objetivo de este artículo es mostrar una revisión bibliográfica de estudios publicados entre 19962007, analizando relaciones específicas entre los tipos de padres y los seis principales comportamientos de riesgo en adolescentes. Adolescentes criados bajo una disciplina autoritaria muestran comportamientos más seguros y menores comportamientos de riesgo al ser comparados con adolescentes que provienen de familias poco autoritarias. El tipo paternal y comportamientos relacionados con la afectividad, comunicación familiar y disciplina predicen importantes mediadores para la formación del adolescente, incluyendo desarrollo académico y adaptación psico-social. Cuidadosas evaluaciones sobre los tipos de padres estándar en poblaciones diversas será una próxima etapa crítica para el desarrollo de intervenciones eficaces y adaptadas culturalmente para la promoción de la salud del adolescente.

DESCRIPTORES: conducta del adolescente; asunción de riesgós; salud del adolescent; relaciones padres-hijo

\section{RELAÇÕES ENTRE MODELOS DE PAIS E COMPORTAMENTOS DE RISCO NA SAÚDE DO ADOLESCENTE: UMA REVISÃO INTEGRATIVA DA LITERATURA}

Pesquisas realizadas durante os últimos 20 anos sugerem que a qualidade da relação entre pais e adolescentes tem obtido impacto significante no desenvolvimento de comportamentos de risco a saúde dos adolescentes. $A$ finalidade deste estudo é apresentar uma revisão bibliográfica de estudos publicados entre o ano de 1996 e 2007 , que analisam relações especificas entre modelos de pais e seis principais comportamentos de risco em adolescentes. Os adolescentes crescidos sob disciplina autoritária demonstraram consistentemente mais comportamentos seguros e menos comportamentos de risco comparados a adolescentes vindos de famílias não autoritárias. O modelo dos pais e comportamentos relacionados a afetividade, comunicação familiar e práticas disciplinares, predizem importantes mediadores na formação do adolescente, incluindo o desenvolvimento acadêmico e o ajuste psico-social. Avaliações cuidadosas de modelos padrões de pais em diversas populações, será uma próxima etapa crítica no desenvolvimento de intervenções eficazes e culturalmente adaptadas, na promoção de saúde a adolescentes.

DESCRITORES: comportamento do adolescente; comportamentos de risco; saúde do adolescente; relações pais-filho

${ }^{1}$ RN, MSN, Doctoral Student, e-mail: newmank@uab.edu; ${ }^{2}$ RN, PhD, e-mail: harrisol@uab.edu. University of Alabama at Birmingham School of Nursing, USA; ${ }^{3}$ PhD, Associate Professor, University of Alabama at Birmingham School of Public Health, USA 
Adolescence is a critical period for the development of healthy behaviors and lifestyles. Findings from numerous studies over the past 20 years suggest that the quality of the parent-adolescent relationship has significant impact on the development or prevention of risky adolescent health behaviors ${ }^{(1-8)}$. Although there are many behaviors that might be considered risky, the Centers for Disease Control and Prevention (CDC) has identified six health risk behaviors as being particularly salient for the development of optimal health. These six risk behaviors include: (a) behaviors that contribute to unintentional injuries and violence; (b) tobacco use; (c) alcohol and other drug use; (d) sexual behaviors that contribute to unintended pregnancy and sexually transmitted diseases; (e) unhealthy dietary behaviors; and (f) physical inactivity ${ }^{(9)}$. These behaviors are often established in early childhood and may continue and intensify through the adolescent period. The health of our children and teens are a priority as reflected in the Healthy People 2010 goals for the nation. The risk taking behaviors that will be addressed in this paper are alcohol, drug and tobacco use, violence and unintentional injuries (including suicide and violence); sexual behaviors; unhealthy dietary behaviors; and physical inactivity ${ }^{(9)}$.

There are many dimensions of the adolescentparent relationship that might influence adolescent health and developmental outcomes, as well as the development of risky health behaviors. Such components include parental warmth versus coldness, acceptance versus rejection, structure versus chaos, autonomy versus control, involvement versus detachment or neglect, strictness versus permissiveness, consistent versus inconsistent discipline, and connection versus distance ${ }^{(10)}$. Specific parenting behaviors that have been found to influence adolescent health and risky health behaviors include type of discipline (consistent versus inconsistent), level of parental involvement, level of parental monitoring, type of communication ${ }^{(11-17)}$, and parenting style ${ }^{(18)}$. In a study $^{(19)}$, parenting style was definied encompassing both contextual and individual aspects of a parent's child rearing, and distinguished this concept from more content- and goal-specific parenting practices and behaviors. Various studies $\left({ }^{1,20-21)}\right.$ proposed that parenting styles vary along two separate dimensions: demandingness (control) and responsiveness (acceptance), and that crossing these dimensions yields separate categories of parenting styles. Some researchers have categorized parents into three parenting style categories if they score in the upper tertiles on measures these two dimensions: authoritarian (high control and low acceptance), authoritative (high control and high acceptance), or permissive/indulgent (low control and high acceptance) ${ }^{(1,18,22-23)}$. Some have added a fourth category of neglectful parenting style (low control and low acceptance) ${ }^{(24)}$. Others have used different operational definitions and measures, although most measures focus on dimensions of control and acceptance $^{(1,16,25-27)}$.

The purpose of this paper is to present a review of studies published between 1996-2007 that address specific relationships between parenting styles and the six priority adolescent risk behaviors identified by the Centers for Disease Control and Prevention $(C D C)^{(9)}$. In order to identify articles for inclusion in this review, we searched the CINAHL, Medline, and Psych Info databases for articles that were published between 1996 and 2007, using the key words of parenting styles, and risky adolescent health behaviors, and cross-listing key words of parenting styles and adolescent with each of the six risky behaviors ( alcohol, drug and tobacco use, violence and unintentional injuries (including suicide and violence); sexual behaviors; unhealthy dietary behaviors; and physical inactivity). The review includes only studies examining specific relationships between parenting styles and substance use, unhealthy eating, and risky sexual behaviors Because we found very few studies examining relationships between parenting styles and low physical activity and parenting styles and intentional or unintentional injury, we expanded the criteria for this section to include studies that examined specific parenting behaviors that are considered components of parenting style (e.g. control, nurturing, acceptance, and communication). This review is organized by first presenting summaries of studies examining relationships with each of the six risky behaviors, and then by examining commonalities and differences across the studies. The paper concludes with a discussion of implications for future research and practice.

\section{RELATIONSHIPS BETWEEN PARENTING STYLES AND USE OF ALCOHOL, DRUGS, AND/OR TOBACCO}

Use of alcohol, drugs, and tobacco poses a significant risk to health of adolescents. Studies suggest that $45 \%$ of older adolescents have tried an illegal drug, nearly $90 \%$ have tried alcohol ${ }^{(28-29)}$, and nearly $40 \%$ 
smoke ${ }^{(30)}$. Fifteen studies were reviewed that examined relationships between parenting styles and adolescent use of drugs and/or alcohol. Consistent with research published prior to 1996, findings from these studies suggested a decreased risk of drug use among adolescents whose parents had an authoritative

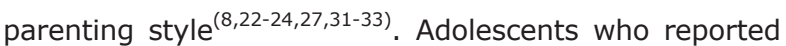
that their parents had authoritative parenting styles were also less likely to initiate or increase their rates of smoking over a 2-year period ${ }^{(34)}$. Although adolescents from authoritative homes reported more smokingspecific discussions with their parents, findings from two studies suggested that parenting style did not moderate the relationship between smoking-specific parenting practices and adolescent smoking ${ }^{(34-35)}$. Various sources ${ }^{(36)}$ reported that although parenting style did not predict smoking experimentation, adolescents who rated their parents as having a parenting style with higher levels of intimacy and autonomy considered a "healthy" parenting style) were less likely to initiate smoking, or more likely to report intention to quit if they had already initiated smoking. In this study ${ }^{(36)}$, the Family of Origin scale was used to measure the level of intimacy and autonomy within the family. The researchers assumed that high levels of intimacy and autonomy reflected optimal parenting styles ${ }^{(18,20-21)}$.

Findings from several studies also indicated that adolescents whose parents had neglectful/ unengaged or authoritarian parenting styles had an increased risk for drinking, smoking, and/or using drugs $^{(8,16,23-26,31,33)}$. Parental permissiveness or indulgence was also associated with increased adolescent alcohol and tobacco use ${ }^{(22,23,27)}$.

Several researchers noted that there were differences in the relationships between parenting styles and adolescent risky behaviors depending on whether the parenting style was rated by adolescents or parents, suggesting the importance of considering both parent and adolescent reports ${ }^{(22,34)}$. One study ${ }^{(22)}$, for example, found that alcohol and tobacco use among a sample of $8^{\text {th }}$ and $9^{\text {th }}$ grade students was associated with a child perception of lower authoritativeness and higher permissiveness, but that there was no relationship between parental perceptions of their parenting style and child alcohol or tobacco use. These researchers concluded that parents may benefit from understanding how their children perceive them, and suggested that even though the child's perception of parenting style may be biased, it was most useful in predicting substance use.
In one research ${ }^{(26)}$ found correlations of .40.46 were found between adolescents' perceptions of caring and protective behaviors of mothers and fathers, and suggested that this high correlation indicated that adolescents perceived their mothers and fathers as having similar parenting styles. However, another study ${ }^{(25)}$ found that adolescents were more likely to rate their mothers as authoritative and less likely to rate them as uninvolved. Other researchers have reported significant gender differences in the strength of relationships between parenting styles and adolescent substance use, and findings suggest that the parenting style of the parent of the same sex has the strongest relationship with self-regulation and substance use ${ }^{(23,31)}$.

Only three studies included an analysis of differences in effects of parenting styles among different racial and ethnic groups, although one source (2006) noted that findings from previous studies have suggested that authoritarian parenting is not as damaging in minority families as in White families. These researchers found that greater parental warmth and family acceptance exerted a stronger impact in reducing drug use among Latinos than among White and Black adolescents ${ }^{(4)}$. A study ${ }^{(22)}$ reported that White students perceived parents as less authoritarian than Hispanic and Asian students, and another ${ }^{(8)}$ found that White parents were more likely to be rated as authoritative, and African-American and Hispanic parents were more likely to be rated as autocratic.

Although there were slight differences across the 15 studies based on the measures used, the gender or ethnicity of the parent and adolescent, and on whether parenting styles were rated by parents or adolescents, the findings were generally consistent, and confirmed research published prior to 1996 which suggested that authoritative parenting is associated with reduced risk of drug or alcohol use. Findings also suggest that authoritarian and neglectful parenting is associated with the greatest risk of substance use, followed by permissive parenting.

\section{RELATIONSHIP BETWEEN PARENTING STYLES AND INTENTIONAL OR UNINTENTIONAL INJURY}

Intentional and unintentional injuries are a major concern during adolescence in the Unites States. According to the Youth Risk Behavior Survey 
unintentional and intentional injuries constitute $70 \%$ of the causes of death among youth aged 10-24 years $^{(37)}$. Intentional injury is defined as deliberate harm to self or others, such as homicide, and violence. Notably, the CDC indicated that suicide is a behavior that contributes to violence, placing suicide in the category of intentional injury. Unintentional injury occurs primarily through automobile accidents during the teen years.

A search of the literature regarding the influence of parenting style on intentional and unintentional injury in adolescents yielded few publications. However, when the search strategy was expanded to include depression, which is a major factor in adolescent suicide, a more substantive body of research was produced. Because there were very few studies specifically examining parenting style, the search was also expanded to include articles that addressed specific parenting behaviors that are often included in measures of parenting style patterns, such as affection, control, discipline and acceptance.

\section{PARENTING STYLE AND INTENTIONAL INJURY}

\section{Depression}

Several studies were located in which researchers examined relationships between adolescent depression and aspects of parenting style such as support or acceptance, discipline, and control, addressed singularly or in various combinations. One study addressed criticism and positive behaviors, and two studies addressed family parenting styles and their relationship to outcomes, including depression ${ }^{(8,38)}$. Another research ${ }^{(39)}$ assessed maternal critical and positive interaction behaviors among mothers of "relatively depressed adolescents", aged 14-18 years, in a predominantly Caucasian but ethnically diverse sample. These mothers were compared with mothers of adolescents who did not have symptoms of depression. Adolescents with depressive symptoms responded to maternal criticism with depressive behavior, in contrast to adolescents without depressive symptoms. Depressed affect in the adolescent was followed by less positive and supportive responses from mothers. Mothers of adolescents who were in the depressed group demonstrated less positive and supportive behavior overall. A study of 175 Mexican- origin families of 11-15 year old adolescents from low income inner city areas in the Southwest U. S. and similarly found that maternal support, defined as acceptance and attachment, was negatively related to adolescent depression ${ }^{(40)}$. A cross-national study of the interrelationships of parenting and adolescent outcomes in the United States and 11 other countries $^{(41)}$ made a sophisticated and complex dominance analysis of three aspects of parenting style, parental support, psychological control and behavioral control, was conducted based on adolescent reports regarding both mothers and fathers. Parental support was consistently linked to lower levels of depressive feeling in adolescents across groups both crosssectionally and longitudinally, demonstrating causal linkages. A research studied the different influences of parenting style on adolescent mental health that were due to acculturative status by examining low income Mexican American and Euro American families of children 8-13 years of age ${ }^{(42)}$. Both Mexican American and Euro American families with low levels of conflict and hostile control, who were accepting and used consistent discipline, were more likely to have children with fewer depressive symptoms and conduct disorder.

One study examined the relationship of controlling parenting style with adolescent depression in a multiethnic balanced sample of Caucasian, Latino and African American girls ${ }^{(43)}$. There was no significant relationship between firm maternal control and depression in Caucasian and Latino girls, but a negative relationship of firm control with depression was found in the African American group. This suggests that the meaning of similar parenting behaviors are differently constructed by different ethnic groups. Firm control may be more normative and adaptive in African American groups, buffering the risk for depression in African-American girls.

Researches examined the contribution of family parenting styles to depression of 451 eighth graders enrolled in a longitudinal study ${ }^{(38)}$. Family parenting styles were formed by combining individual styles of two parents, who were classified as authoritative, authoritarian, indulgent, or uninvolved based on youth ratings and research observation. When at least one parent was authoritative, children had significantly lower levels of depression as well as delinquency. Family parenting style explained $11 \%$ of the variance in adolescent depression. A combination of an authoritative parent with either an 
authoritative or indulgent parent, or a combination of two indulgent parents were associated with better outcomes than a combination of an uninvolved mother and an indulgent or uninvolved father.

An examination ${ }^{(8)}$ of relationships between parenting styles and depression among 3,993 15year-olds in California found that adolescents who reported that their parents had an authoritative style were least likely to have depressive symptoms, followed by adolescents who had permissive, autocratic, and unengaged parenting. These authors identified three subgroups at particular risk for depression: African-American boys with unengaged parents, and Asian girls with either autocratic or unengaged parents.

In summary, parental support demonstrated a negative relationship with depression across studies and cultural groups. In addition, although hostile control demonstrated a positive relationship with adolescent depression in one study, firm control demonstrated a negative relationship with adolescent depression among African American families. Slight evidence suggests a positive relationship of inconsistent discipline with adolescent depression. An authoritative parenting style by at least one parent appears to protect the adolescent from depression, whereas uninvolvement poses a risk for depression.

Suicide

Parental caring, warmth, control, conflict, and authoritarianism have been examined in relation to adolescent suicidal ideation or self-harm. Authors found that more negative touch from family and friends and less positive touch was related to greater suicidal ideation and deliberate self-harm among 1315 year old middle class Caucasian adolescents ${ }^{(44)}$. Moreover, more frequent positive touch and less frequent negative touch were associated with perceptions of parental caring, suggesting that physical contact may reflect differences in parenting style. Lai and McBride-Chang compared two groups of Hong Kong adolescents, aged $15-19^{(45)}$. One group was experiencing suicidal ideation and the other was not. Those with suicidal ideation perceived mothers and fathers to be significantly more authoritarian, perceived mothers to be significantly more over controlling and perceived the family climate to be significantly more conflictual and less warm. Similarly, Toumbourou and Gregg found that $12 \%$ of Australian $8^{\text {th }}$ grade students had experienced suicidal thoughts or had harmed themselves deliberately ${ }^{(46)}$. The rate of this behavior was double for those who were low on maternal and paternal care. Rates of suicidal behavior were higher for those who were low or high, versus moderate, in maternal or paternal control. Similarly, female Israeli adolescents manifesting deliberate self-poisoning perceived their mothers as less caring and more controlling than non-selfharming adolescents. This parenting style was labeled "affectionless control"(47).

In summary, parental caring and warmth bear a consistent negative relationship with suicidal ideation and self-harm, as demonstrated in three cultures. Parental controlling behavior and conflict within the family or parent-adolescent dyad appear to be positively related to suicidal ideation and behavior in an Asian and Australian group. However, the number of studies in this area is limited.

Violence

Only one study was located that addressed parenting style and adolescent violence ${ }^{(48)}$. African American adolescents, aged 11-14 years, responded to questions about parental style (authoritative, authoritarian, or permissive) of their mothers and also described their reactions to hypothetical situations that might produce violent reactions. Their anticipated reactions were rated for violence. Adolescents who described their mother as using a permissive parenting style were more likely to demonstrate a tendency to anticipate a more violent response to the hypothetical situation.

\section{PARENTING STYLE AND UNINTENTIONAL INJURY}

No studies of parental style and adolescent injury were located. However, one research studied the relationship of supervision of children and their unintentional injury risk ${ }^{(49)}$. Children with behavioral disorders and their mothers were observed in a "hazard room" that contained items that appeared dangerous, but were not. Maternal ignoring of children's dangerous behavior in the room was related to children's injury history. This suggests the further need to study parenting styles of disengagement or diminished monitoring as they contribute to injury risk. 


\section{RELATIONSHIP BETWEEN PARENTING STYLES AND UNHEALTHY SEXUAL BEHAVIORS}

In an examination of ${ }^{(50)}$ the relationship between parenting monitoring and communication and adolescent sexual risk behavior among a group of 2,701 students enrolled in six rural high schools in the southeastern United States, logistic regression analysis revealed a direct relationship between sexual risk taking and parental monitoring and communication. Those adolescents who were closely supervised by their parents had a lower amount of sexual risk taking than those adolescents who had low amounts of parental monitoring or supervision. Variables of age, gender, and race demonstrated no relationship with sexual risk behavior. Data collected were based on the adolescent self report, and the authors recommended that future studies should include measures of parents' perceptions of parenting style, and consider differentiating between the gender for both the adolescent and the parent.

Lookink $\mathrm{at}^{(12)}$ the relationships between maternal parenting style and adolescent sexual behavior in a sample of 253 British adolescent-mother dyads, parenting style was found to be directly associated with the delay of the first sexual experience for the adolescent between the ages of 15-16 years of age. For the older adolescent, this was not true. These findings suggest that parental styles have a greater influence in the adolescent's sexual attitude and behavior in the early teen years verses the later years and that parental influences decrease for the older adolescent.

\section{RELATIONSHIP BETWEEN PARENTING STYLES AND UNHEALTHY EATING PRACTICES AND PHYSICAL INACTIVITY}

Two studies were located that examined the relationship between parenting styles and unhealthy eating practices, but no studies were identified examining relationships between parenting styles and physical inactivity. One of them ${ }^{(51)}$ examined the relationship between parenting styles and adolescent food choices in a cross-sectional study of 1771 Dutch adolescents between 16-17 years of age. The authors hypothesized that children of authoritative parents would consume an increased amount of fruits and vegetables than those of nonauthoritative parents. The findings demonstrated that there was a relationship between the parental style in the home and the consumption of fruits. Those adolescents from authoritative homes had healthier eating behaviors than those adolescents from indulgent homes. The researchers used the adolescent reports of parenting style, but acknowledged that the adolescent reports may be different from the parent reports. The type of parenting style reported by the adolescent differed in relation to adolescent age and gender. An authoritative parental style was reported more often by the younger adolescent than the older adolescent. The indulgent parenting style was reported more often by males than females. Because this study did not differentiate between single and two-parent family structures, further exploration of the parenting influences on dietary behaviors of children and adolescents based on the type of family structure is needed.

The other study ${ }^{(52)}$ examined the predictors of fruit and vegetable consumption of adolescents by exploring effects of parental styles and spirituality with a simple of 3878 7th graders who were enrolled in 16 public schools in Minnesota. Greater intake of fruits and vegetables was associated with reports of authoritative parenting style and with reports of spirituality being an important part in the life of the adolescent.

\section{DISCUSSION}

The substantial influence of parenting style on adolescent development is clear. Adolescents raised in authoritative households consistently demonstrate higher protective and fewer risk behaviors than adolescents from non-authoritative families. There is also considerable evidence to show that parenting styles and behaviors related to warmth, communication, and disciplinary practices predict important mediators including academic achievement and psychosocial adjustment ${ }^{(53)}$. Other research has shown that authoritative parenting processes contribute to children's adjustment through the development of self-regulation and resistance efficacy ${ }^{(54)}$. The potential of parents to mediate or buffer the effects of other risks is key, especially in view of the many moderators of youth risk behavior that are not amenable to intervention. If parenting practices can be enhanced, they hold the potential to 
reduce the effect of less-changeable moderators (such as media exposure, poverty and neighborhood risks) on subsequent youth behavior. Comparing and synthesizing research from multiple studies brings inherent limitations that should be noted. Each of these studies had limitations ranging from single informants, an inability to differentiate rating of mothers and fathers or consider differences in relationships based on parents' and adolescents' gender or ethnicity. Measurement issues present another potential source of bias, in that different measures and parenting style typologies were used in various studies in the absence of any "gold standard" measure shown to be appropriate across diverse populations. In addition, even with well validated measures of parenting typology, a significant number of families cannot be distinctly classified into one of the four parenting style categories $^{(1)}$. Future research is needed to study how inconsistent or mixed parenting styles influence adolescent cognitive processes and behavioral outcomes. Another limitation is that most of the studies included in this review are cross-sectional and not longitudinal. There are also a number of methodological limitations that relate to the difficulty in identifying the effects of various confounders and contextual factors that carry great weight in shaping behavior among youth. For example, much research on parenting styles does not assess parental risk behaviors and their influence on their child's risk behaviors. In looking at adolescent health risk behaviors, however, parental modeling of those specific behaviors is especially important. Parents are their child's most influential teachers, exerting tremendous influence on their child's risk-taking behaviors by way of example (i.e., smoking, drinking, poor eating and exercise habits). Similarly, parents influence their child's behaviors by way of their values and their expectations for their child. For example, adolescent perception of their parent's disapproval of early sex has been positively correlated with delayed initiation $^{(55)}$ and future development of sexually transmitted infections ${ }^{(56-57)}$. Future research

\section{REFERENCES}

1. Baumrind $D$. The influence of parenting style on adolescent competence and substance use. J Early Adolesc. 1991; 11(1): 56-95

2. Baumrind D. Rearing competent children. In: RLearner $R$, Petersen AC, Brooks-Gunn J, editors. The encyclopedia on adolescence. New York: Garland; 1991. p.746-58. will need to examine these and other important but unmeasured factors using more sophisticated methodological tools than those presently available.

The magnitude of influence that parenting styles and behaviors exert on youth risk and protection indicates a clear need for more research-based, family-centered interventions to improve adolescent health outcomes. Along with this, a clearly specified conceptual framework to guide family intervention development, implementation, evaluation and dissemination will be needed to successfully move forward, and should be another important focus of future research. More research is also needed to better understand the optimal time to intervene with parents and families to most effectively reduce adolescent health risk behaviors.

Although it is frequently acknowledged that adolescent risk behaviors often co-occur, and although there have been many studies examining the relationship between parenting styles and individual adolescent risk behaviors, no published review articles to our knowledge have reviewed studies across all major categories of risk behaviors collectively and compared their similarities and differences. In our review examining how various parenting styles influence adolescent health risk behaviors, our findings support those of previous similar studies indicating that adolescents of authoritative parents who have positive parental relationships, healthy open communication and perceived parental support, are less likely to report symptoms of depression or engage in substance use, sexual risk and violent behaviors. Our review extends the existing literature by demonstrating that adolescents benefit from authoritative parenting practices across numerous domains, including five of the six focused on by $\mathrm{CDC}$ as critical issues threatening adolescent health. The only behavior lacking evidence for an effect of parenting style is physical activity. Careful examination of parenting style patterns in diverse populations, particularly as they relate to physical activity and unintentional injury will be a critical next step in the development of efficacious, culturally tailored adolescent health promotion interventions.
3. Bonell C, Allen E, Strange V, Oakley A, Copas A, Johnson $A$, et al. Influence of family type and parenting behaviours on teenage sexual behaviour and conceptions. J Epidemiol Community Health. 2006; 60(6):502-6.

4. Broman CL, Reckase MD, Freedman-Doan CR. The Role of Parenting in Drug Use Among Black, Latino and White Adolescents. J Ethn Subst Abuse. 2006; 5(1):3950 . 
5. Chapman RP. Parenting characteristics in predicting adolescent smoking and drinking expectancies and intentions: ProQuest Information \& Learning; 2002.

6. DeVore ERMD, Ginsburg KRMD. The Protective Effects of Good Parenting on Adolescents. Postgrad Obstet Gynecol. 2005; 25(25):1-5.

7. Fromme K. Parenting and other influences on the alcohol use and emotional adjustment of children, adolescents, and emerging adults. Psychol Addict Behav. 2006; 20(2):138-9. 8. Radziszewska B, Richardson JL, Dent CW, Flay BR. Parenting style and adolescent depressive symptoms, smoking, and academic achievement: Ethnic, gender, and SES differences. J Behav Med. 1996; 19(3):289-305.

9. Eaton DK, Kann L, Kinchen S, Ross J, Hawkins J, Harris WA, et al. Youth risk behvior surveillance - United States, 2005. Atlanta, Georgia: Centers for Disease Control and Prevention; 2006.

10. Skinner E, Johnson S, Snyder T. Six dimensions of parenting: a motivational model. Parent Sci Pract. 2005; 5(2): $175-235$.

11. van der Vorst H, C. M. E. Engels R, Meeus W, Dekovic M, Vermulst A. Family Factors and Adolescents' Alcohol Use: A Reply to Chassin and Handley (2006) and Fromme (2006). Psychol Addict Behav. 2006; 20(2):140-2.

12. Taris TW, Semin GnR. How mothers' parenting styles affect their children's sexual efficacy and experience. J Gen Psychol. $1998 ; 159(1): 68-81$.

13. Swadi $H$. Individual risk factors for adolescent substance use. Drug Alcohol Depend. 1999; 55(3):209-24.

14. Sieverding JA, Adler N, Witt S, Ellen J. The influence of parental monitoring on adolescent sexual initiation. Arch Pediatr Adolesc Med. 2005; 159(8):724-9.

15. Rhee KE, Lumeng JC, Appugliese DP, Kaciroti N, Bradley $\mathrm{RH}$. Parenting styles and overweight status in first grade. Pediatrics. 2006; 117(6):2047-54.

16. Myers HF, Newcomb MD, Richardson MA, Alvy KT. Parental and family risk factors for substance use in innercity African-American children and adolescents. J Psychopathol Behav Assess. 1997; 19(2):109-31.

17. Gonzales NA, Knight GP, Morgan-Lopez AA, Saenz DS, A. Acculturation and the mental health of Latino youths: An integration and critique of the literature. In: Contreras JM, Kerns KA, Neal-Barnett AM, editors. Latino children and families in the United States. Westport, Connecticut: Praeger; 2002. p.45-74.

18. Baumrind D. Current patterns of parental authority. Develop Psychol 1971;4:1-103

19. Grigorenko EL, Sternberg RJ. Elucidating the ethiology and nature of beliefs about parenting styles. Develop Sci. 2000; 3(1):93-112.

20. Baumrind D. Parental disciplinary patterns and social competence in children. Youth Soc. 1978;9(239-276).

21. Baumrind D. Child care practices anteceding three patterns of preschool behavior. Gen Psychol Monogr. 1967; 75(43-48).

22. Cohen DA, Rice J. Parenting styles, adolescent substance use, and academic achievement. J Drug Educ. 1997; 27(2):199-211.
23. Patock-Peckham JA, Cheong J, Balhorn ME, Nagoshi CT. A social learning perspective: A model of parenting styles, self-regulation, perceived drinking control, and alcohol use and problems. Alcohol Clin Exp Res. 2001; 25(9):1284-92. 24. Adalbjarnardottir S, Hafsteinsson LG. Adolescents' perceived parenting styles and their substance use: Concurrent and longitudinal analyses. J Res Adolesc. 2001; 11(4):401-23.

25. Bronte-Tinkew J, Moore KA, Carrano J. The Father-Child Relationship, Parenting Styles, and Adolescent Risk Behaviors in Intact Families. J Fam Issues. 2006; 27(6): 850-81.

26. Clausen S-E. Parenting styles and adolescent drug use behaviours. Childhood: A Global Journal of Child Research. 1996; 3(3):403-14.

27. Slicker EK. Relationship of parenting style to behavioral adjustment in graduating high school seniors. J Youth Adolesc. 1998; 27(3):345-72.

28. Harrison LD, Poettiger AE. The epidemiology of drug use among American youth. In: McCoy $\mathrm{CB}$, Metsch LR, Inciard $J A$, editors. Intervening with drug-involved youth. Thousand Oaks, CA: Sage 1996.

29. Weinberg NZ, Radhert E, Colliver JD, glantz MD. Adolescent substance abuse: A review of the past 10 years. J Am Acad Child Adolesc Psychiatry. 1998; 37(3):252-61. 30. Prevention CfDCa. Youth tobacco surveillance surveyUnited States. MMWR Morb Mortal Wkly Rep. 2001; 50:1-84. 31. Patock-Peckham JA, Morgan-Lopez AA. College Drinking Behaviors: Mediational Links Between Parenting Styles, Impulse Control, and Alcohol-Related Outcomes. Psychol Addict Behav. 2006; 20(2):117-25.

32. Stephenson MT, Quick BL, Atkinson J, Tschida DA. Authoritative parenting and drug-prevention practices: Implications for antidrug ads for parents. Health Commun. 2005; 17(3):301-21.

33. Weiss $\mathrm{LH}$, Schwarz C. The relationship between parenting types and older adolescents' personality, academic achievement, adjustment, and substance use. Child Develop. 1996; 67(5):2101-14.

34. Chassin L, Presson CC, Rose J, Sherman SJ, Davis MJ, Gonzalez JL. Parenting Style and Smoking-Specific Parenting Practices as Predictors of Adolescent Smoking Onset. ] Pediatr Psychol. 2005; 30(4):334-44.

35. Huver RME, Engels RCME, Vermulst AA, defries $H$. Is parenting style a context for smoking-specific parenting practices? Drug Alcohol Depend. 2007; 89:116-25.

36. O'Byrne KK, Haddock cK, Poston WSC, Institutte MAH. Parenting style and adolescent smokin. J Adolesc Health. 2002; 30(6):418-25.

37. Danice K, Eaton DK, Kann L, Kinchen S, Ross J, Hawkins J, Harris WA, Lowry R, et al. Prevention CfDCa. Youth Risk Behavior Surveillance-United States, 2005 MMRW Surveill Summ 2006; 55(SS-5):1-108.

38. Simons LG, Conger RD. Linking mother-father differences in parenting to a typology of family parenting styles and adolescent outcomes. J Fam Issues. 2007; 28:212-41. 39. Pineda AQ, Cole DA, Bruce AE. Mother-adolescent interactions and adolescent depressive symptoms: A sequential analysis. J Soc Pers Relat. 2007; 24:5-19. 
40. Gonzales NA, Deardorff J, Formoso D, Barr A, Barrera M. Family mediators of the relation between acculturation and adolescent mental health. Fam Relat. 2006; 55:318-30.

41. Barber BK, Stolz HE, Olsen JA. Trajectories of physical aggression from toddlerhood to middle childhood. Monogr Soc Res Child Dev. 2005; 70:1-137.

42. Hill NE, Bush KR, Roosa MW. Parenting and family socialization strategies and children's mental health: Lowincome Mexican-American and Euro-American mothers and children. Child Develop. 2003; 74:189-204.

43. Finkelstein JS, Donenberg GR, Martinovich Z. Maternal control and adolescent depression: Ethnic differences among clinically referred girls. J Youth Adolesc. 2001; 30:155-72. 44. Pearce CM, Martin G, Wood K. Significance of touch for perceptions of parenting and psychological adjustment among adolescents. J Am Acad Child Adolesc Psychiatry. 1995; $34: 160-7$.

45. Lai KW, McBride-Chang C. Suicidal ideation, parenting style, and family climate among Hong Kong adolescents. Int J Psychol. 2001; 36:81-7.

46. Toumbourou JW, Gregg ME. Impact of an empowermentbased parent education program on the reduction of youth suicide risk factors. J Adolesc Health. 2002; 31:277-85.

47. Diamond GM, Didner H, Waniel A, Priel B, Asherov J, Arbel S. Perceived parental care and control among Israeli female adolescents presenting to emergency rooms after selfpoisoning. Adolescence. 2005; 40:257-72.

48. Miller JM, Dilorio C, Dudley W. Parenting style and adolescent's reaction to conflict: Is there a relationship? . J Adolesc Health. 2002; 3:464-8.

49. Schwebel DC, Hodgens JB, Sterling S. How mothers parent their children with behavior disorders: Implications for unintentional injury. J Safety Res. 2005; 37:167-73.

50. Huebner AJ, Howell LW. Examining the relationship between adolescent sexual risk-taking and perceptions of monitoring, communication, and parenting styles. Journal of Adolescent Health. 2003; 33(2):71-8.

51. Kremers SPJ, Brug J, de Vries H, Engels RCME. Parenting style and adolescent fruit consumption. Appetite. 2003; 41 (1):43-50.

52. Lytle LA, Varnell S, Murray DM, Story M, Perry C, Birnbaum AS, et al. Predicting adolescents' intake of fruits and vegetables. Journal of Nutrition Education \& Behavior. 2003; 35(4):170-8. 53. Cutrona CE, Cole V, Colangelo N, Assouline SG, Russell DW. Perceived parental social support and academic achievement: an attachment theory perspective. J Pers Soc Psychol. 1994 Feb; 66(2):369-78.

54. Wills TA, Gibbons FX, Gerrard M, Murry VM, Brody GH. Family communication and religiosity related to substance use and sexual behavior in early adolescence: a test for pathways through self-control and prototype perceptions. Psychol Addict Behav. 2003 Dec; 17(4):312-23.

55. Dittus PJ, Jaccard J. Adolescents' perceptions of maternal disapproval of sex: Relationship to sexual outcomes. J Adolesc Health. 2000; 26:268-78.
56. Ford CA, Pence BW, Miller WC, Resnick MD, Bearinger LH, Pettingell S, et al. Predicting adolescents' longitudinal risk for sexually transmitted infection: results from the National Longitudinal Study of Adolescent Health. Arch Pediatr Adolesc Med. 2005 Jul; 159(7):657-64.

57. St Lawrence JS, Brasfield TL, Jefferson KW, Alleyne E, O'Bannon RE, 3rd, Shirley A. Cognitive-behavioral intervention to reduce African American adolescents' risk for HIV infection. J Consult Clin Psychol. 1995 Apr; 63(2):22137. 